\title{
La villa de Cabra en el Antiguo Régimen: La peste de 1648 a 1651
}

Francisco de Borja luque Muriel

Las guerras, las crisis de subsistencias y las epidemias fueron las tres parcas que marcaron el comportamiento demográfico en la Edad Media y en el Antiguo Régimen. Esta situación aparece claramente reflejada en la España del siglo XVII, época histórica interesantísima para el ulterior desarrollo peninsular.

No desgranaremos, los acontecimientos acaecidos a mediados de ese Siglo de Crisis, aunque es necesario resaltar hechos tales como, allende nuestras fronteras, la imposición del equilibrio europeo de Westfalia y el apéndice de ese sistema con la lucha franco-española y la firma del Tratado de los Pirineos, tácito reconocimiento de la supremacía francesa y del inicio del fin del Imperio español. Estos acontecimientos internacionales coincidieron y tal vez alentaron los problemas hispanos, así la lucha centro-periferia (independencia de Portugal, sublevaciones catalana, aragonesa y andaluza), las cuestiones derivadas de la disminución de la llegada de metal americano, así como crisis de subsistencias que provocaron motines populares.

No obstante, en este trabajo prescindiremos de esas cuestiones abordadas por excelentes historiadores y nos ceñiremos a plantear un panorama global sobre la villa de Cabra en el Antiguo Régimen concluyendo con la crítica situación que la localidad vivirá entre 1648 y 1651 por causa de la peste. 


\section{LOCALIZACIÓN GEOGRÁFICA DE LA VILLA DE CABRA}

Cabra está situada a $72 \mathrm{Kms}$ de Córdoba, al sur de esta provincia y localizada en la zona ocupada por las cordilleras béticas, concretamente en el complejo subbético frontal, externo o jurásico calizo en su zona septentrional.

En la actualidad su término municipal comprende $227,50 \mathrm{Kms}$ cuadrados, limitando con los términos de Montilla, Nueva Carteya y Doña Mencía por el norte; con los de Monturque, Lucena y Rute por el sur; con los de Baena, Doña Mencía, Zuheros y Carcabuey por el este y por el oeste con los de Montilla, Monturque y Baena. La fijación definitiva de su superficie se produjo en el siglo XIX, con pequeñas variaciones en los años 20 del presente siglo.

Según los datos recogidos en el Catastro de Ensenada a mediados del siglo XVIII el término «... de esta villa consiste en doce leguas de circunferencia, señaladamente tres y media de longitud de Levante a Poniente y dos y media de latitud del Norte al Sur, poco más o menos, y consiguientemente a la dicha circunferencia doce horas, por alguna aspereza que por artes ocupa el territorio y que éste linda por Levante con las villas de Carcabuey, Zuheros y Doña Mencia y sus mojones, por Poniente con las villas de Aguilar y Monturque y las suyas, por el Norte con la ciudad de Montilla y las villas de Castro y Baena y sus mojones, y por el Sur con la ciudad de Lucena y las villas de Rute y las suyas..." ${ }^{1}$.

En líneas generales los términos municipales en el XVIII $y$ en la actualidad son similares, con las variaciones de Nueva Carteya -inexistente en el Antiguo Régimen-y limitando en la actualidad con las poblaciones de Aguilar y Castro del Río.

Su perímetro abarcaba doce leguas, $65,872 \mathrm{Kms}$, siendo más amplio de este a oeste con una longitud en este sentido de $18,5 \mathrm{Kms}$ y de norte a sur algo más de $14^{2}$.

\footnotetext{
Respuesta $3 .^{a}$ del Interrogatorio General del Catastro de Ensenada.

J. Calvo Poyato y J. L. Casas Sánchez, La villa de Cabra en el siglo Xvili. Cabra
} 1980. 
En cuanto a las características geográficas podemos observar una serie de peculiaridades.

Geomorfológicamente aparecen una serie de subzonas:

- Valle del río Cabra, situado en la vertiente occidental de su Sierra, se extiende de este a oeste, desde la Fuente del Río hasta la parte meridional de la ciudad, tomando después dirección sur llegando después a la llanura de Monturque ${ }^{3}$.

- Campiña margosa o zona de transición a las elevaciones calizas, ocupando la mayor parte del término municipal, con cultivos alternativos de olivo, vid y cereal sobre calizas y margas yesíferas.

- Macizo de Cabra, extremidad norte del espolón montañoso con orientación SE-NW, teniendo una porción norte constituida por elevaciones que se sitúan en torno a los 1.000 metros (Lanchares, Camarena), culminando en el Picacho de la Sierra y Lobatejo (1.380 metros), éste último perteneciente al término de Carcabuey. Estos terrenos no son aptos para cultivos, siendo únicamente aprovechables para pastos.

- Finalmente, encontramos una subzona denominada genéricamente «monte», que abarcaría la citada anteriormente y el conjunto de lomas bajas que la limitan (Carmona, Jarcas, Carmonilla, Hoyones, etc.), así como las existencias al norte de la ciudad (Atalaya y Calvario).

En relación con la hidrografía, la ubicación en su término del Macizo de Cabra -extensa mole de 80 a $100 \mathrm{Kms}$ cuadrados que se introduce en los municipios circundantes - hace que aparezcan dos cuencas, una al sur de la carretera de Priego a Cabra - constituida por la zona de Jarcas y Gaena - y otra incluye la Sierra de Cabra y Camarena entre otras. Ambas zonas, con precipitáciones muy abundantes, presentan en el término los siguientes manantiales y ríos, éstos de escasa importancia:

- El manantial de la Fuente del Río, situado a $2 \mathrm{Kms}$ de la población, es el más relevante, bifurcándose desde su nacimiento en un ramal que abastece a la población y en otro que surte las acequias del $\mathrm{Caz}$, La Vega, El Pedroso y La Madre Vieja del Río, formando a continuación

3 Ayuntamiento de Cabra, Memoria anual, 1985. 
el río Cabra que, después de avenar el valle y circundar la ciudad por la parte sur, entrando por El Mojardín y siguiendo esta misma dirección, riega las huertas hasta llegar al Vado de la Benita en los llanos de Monturque.

- En la Sierra de Camarena se forma el arroyo de Santa María con las aguas de la Fuente de Villanueva, inclinándose hacia el sur, y, recogiendo las aguas de arroyos como los Frailes, Medinilla, Las Cañas, Vadohondillo y el de las Pozas, afluye al río Cabra por los Llanos de Monturque.

- Otros arroyos de menor importancia son el Guadalazar, el arroyo Carchena - llamado también de La Tejedera o Tejera y que circunda el casco urbano por su parte NW-, el de Las Pozas, El Bailón y el arroyo Riofrío.

\section{DESCRIPCIÓN DE SU CASCO URBANO}

El caso urbano egabrense tiene como punto de referencia la zona antigua, delimitada por los barrios de la Villa Vieja y El Cerro de San Juan, situados ambos en dos pequeñas elevaciones entre las que discurre el valle donde se localiza el resto de la población. El barrio del Albaicín - con, tal vez, reminiscencias moriscas- se ubica entre el camino de Córdoba, lindando con la calle San Martín, el arroyo de La Tejedera y la calle Alcaidesa.

Hacia el este nos encontramos el resto del entramado urbano delimitado por la ermita de Sarita Ana en el este y en el sureste por el Convento de los Dominicos, y por el arroyo de la Tejedera en el norte y el río Cabra en el sur.

Esta situación permite cerrar casi con perfección la villa en casos de emergencia, quedando exclusivamente abiertas las puertas que comunicarían el casco urbano con el ruedo o zona de huertas. 


\section{DEMOGRAFÍA}

Determinar la población en la Edad Moderna plantea algunas dificultades, puesto que aún el siglo XVIII se considera período precensal, a pesar de los intentos realizados en la centuria para elaborar censos (Campoflorido, Catastro de Ensenada, Campomanes, Floridablanca).

No obstante, existen bastantes estudios para determinar la población egabrense durante la Edad Moderna.

Eladio de la Presa analiza un documento de 1577 conservado en el archivo de la Real Chancillería de Granada ${ }^{4}$; en él aparecen anotados por sus domicilios los vecinos egabrenses, dando un total de 2.156, mientras que Ortega Alba ${ }^{5}$ recoge 1.616 en las "Relaciones remitidas por MM. RR. Arzobispos RR. Obispos y otros prelados a D. Felipe II por mano de Francisco González de Heredia». Esto nos permite señalar que en la segunda mitad del siglo XVı la población egabrense se situaba en torno a los 8.000 habitantes, cifra extraordinariamente elevada.

Calvo Poyato ${ }^{6}$ hace un estudio de la demografía egabrense en el XVII a través de diferentes repartimientos, así en 1608 se recogen 1.645 vecinos, en 1657 hay 1.640 , en el 65 son 1.642, mientras que en el 1676 aparecen 1.535 vecinos; para el siglo XVIII hemos de tener como referencia al Catastro de Ensenada, donde se reflejan 2.156 vecinos.

Esos altibajos en la población, como perfectamente apunta el doctor Calvo Poyato, se deben a diferentes causas: la expulsión de los moriscos a principios del siglo XVII, las diferentes epidemias de peste, la necesidad de aportar soldados para la guerra, así como la crisis económica general.

El final del siglo XVII y el siglo XVIII llevarán a la recuperaciórı demográfica, precedente del «boom» demográfico egabrense del siglo XIX.

En cuanto a la estructura social de la época, tenemos mayores datos sobre el XVIII a través de ese excelente documento histórico cual es el

\footnotetext{
J. Calvo Poyato, La villa de Cabra en la crisis del siglo XVII. Cabra 1979.
} p. 125.

«El repartimiento en la villa de Cabra», La Opinión, n. ${ }^{\circ} 2.467$, Cabra 1971.

F. ORTEGa Alba, El Sur de Córdoba: estudios sobre geografia agraria. Córdoba 1977, 
Catastro de Ensenada. Así según la respuesta 22 del Interrogatorio General encontramos:

- 1.100 jornaleros -incluyendo en este grupo a 29 soldados - que junto con 240 pobres de solemnidad forman los estratos sociales más bajos del pueblo llano. Los primeros venden sus brazos por un salario mínimo y por un trabajo eventual, laborando de sol a sol como obligan las normas para estar constantemente asediados por el hambre, principalmente en períodos de crisis; jornaleros y pobres que acuden constantemente a la caridad pública.

- Por encima de aquéilos se encontrarían los 200 labradores «... por su mano, en que se incluyen los hortelanos por ser éstos como tales...». Es decir, son los pequeños propietarios que acompañan a los anteriores en sus penurias durante épocas de malas cosechas.

- En el estado llano se hallan también los artesanos agremiados —desde aprendices a maestros-, así como comerciantes y otros miembros del sector terciario.

- La Iglesia, el clero, cuenta con 240 vecinos - considerando tanto a los clérigos que forman "cabeza de casa" como a los miembros de las comunidades religiosas-. Salvo excepciones, tampoco podrian presumir de unia situación económica desahogada.

- A la cabeza de la pirámide social aparecían los hidalgos y otros miembros de la nobleza.

Según Calvo y Casas $^{7}$ porcentualmente la estratificación social sería:

— Hidalgos: $2,00 \%$.

- Clero: 11,12\%.

- Artesanos: $11,12 \%$.

- Comercio y otros: $6,15 \%$.

- Labradores: 9,00\%.

- Jornaleros: $49,75 \%$.

- Pobres: 10,86.

7 J. Calvo Povato y J. L. Casas Sánchez, obra citada, p. 67 y ss. 


\section{GOBIERNO DE LA VILLA}

Hemos hablado de las características geográficas y demográficas de Cabra, sin embargo no hemos hecho referencia a su situación jurídica.

La villa es de señorío, y su gobierno pertenece al duque de Sessa como conde de Cabra. No llegaba a ser un señorío solariego -o territorial- puesto que el señor no era propietario de la totalidad de la tierra del municipio; sí actuaba como señor jurisdiccional ya que nombraba los cargos municipales, controlaba las escribanías públicas, poseía los monopolios de molinos, hornos, lagares y mesones -aunque en ocasiones permitía la entrada de particulares como propietarios-, percibía las Tercias Reales, rentas de pescado, jabón, etc.; y ejercía el patronazgo sobre la mayor parte de las cofradías, conventos e instituciones benéficas de la villa.

La provisión de los cargos por parte del duque se refleja en la documentación conservada tanto en el Catastro como en la documentación conservada en el Archivo Municipal de Cabra.

El duque designaba al alcalde mayor - que habitualmente se autodenominaban "corregidores", nombre del representante real en las villas dependientes directamente del monarca-, al teniente de alcalde, al alguacil mayor, a los regidores, al procurador síndico, a los jurados, al alcalde de la Hermandad, al Padre general de menores, etc., según recoge el Catastro.

Igualmente el duque nombraba otros «oficios anuales» como el superintendente del Pósito, diputado para la compra de trigo al Pósito, procurador mayor del Consejo, diputado de Guerra, mayordomo del Pósito, mayordomo de propios y arbitrios, diputado de pozas, apreciadores, alarifes, vendedores, etc.

\section{LA ACTIVIDAD ECONÓMICA DE LA VILLA}

El mejor instrumento para el conocimiento de la actividad económica egabrense durante el Antiguo Régimen es el Catastro de Ensenada. 
El término municipal en el siglo xvIII se componía de 23.696, lo que suponen $148,538 \mathrm{Kms}$ cuadrados. Estas cifras contrastan con la extensión actual, 227,540 Kms cuadrados; las causas de esto son varias:

- En primer lugar, las diferentes ampliaciones que se han llevado a cabo desde esa fecha hasta su delimitación actual.

- Igualmente puede suceder, como señala Cruz Villalón ${ }^{8}$, que haya ocultaciones y falta de precisión en las mediciones efectuadas en aquel entonces, especialmente en las especies menos productivas.

En resumen la distribución sería:

\begin{tabular}{|c|c|c|}
\hline & Fanegas & $(\%)$ \\
\hline Tierra de secano & 8.211 & 34,65 \\
\hline Olivares .... & 7.200 & 30,38 \\
\hline Viñedos .... & 3.600 & 15,19 \\
\hline Tierra de regadio & 500 & 2,11 \\
\hline Tierra yerma & 2.160 & 9,11 \\
\hline Manchones y matorrales & 900 & 3,79 \\
\hline Tierra de calidad inferior & 600 & 2,53 \\
\hline 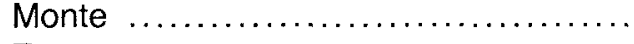 & 300 & 1,26 \\
\hline Zumaque $\ldots \ldots \ldots \ldots \ldots \ldots \ldots \ldots \ldots \ldots$ & 100 & 0,42 \\
\hline Puéblo y otros $\ldots \ldots \ldots \ldots \ldots \ldots \ldots \ldots \ldots \ldots \ldots \ldots$ & 119 & 0,49 \\
\hline TOTAL & 23.696 & 100 \\
\hline
\end{tabular}

En cuanto al aprovechamiento general del suelo observaremos como un total de 19.511 fanegas aparecen cultivadas (tierra de secano, olivar, vid y tierra de regadío), lo que supone un $82,33 \%$ del total de la superficie catastrada; por el contrario, 4.179 fanegas - un 17,61\%- no están roturadas; no olvidemos que parte de la superficie municipal se introduce en las Subbéticas.

La variación de los datos analizados es observable si, en vez de hacer referencia al Interrogatorio General, se utilizan los libros de propiedades. Así, según éstos últimos, son 16.250 fanegas las ocupadas por el

8 J. CRuz VILLALÓn, Propiedad y uso de la tierra en la Baja Andalucía, siglos XVIII-XX. Madrid 1981, p. 54. 
secano, 700 por el regadío, 6.700 por el olivar y 3.350 por la vid, 10 que aumenta en más de 3.000 fanegas lo recogido por el Interrogatorio General. Siguiendo este último, la utilización del suelo en la villa de Cabra estaría más próxima a la de Carmona (Sevilla) ${ }^{9}$, donde el porcentaje de superficie útil es de $86,55 \%$, que al de la campiña cordobesa, comarca más próxima a Cabra, donde López Ontiveros calcula un 30,6\% de superficie inculta ${ }^{10}$.

No vamos a entrar en el estudio de la estructura de la propiedad en Cabra, ya que este tema está perfectamente elaborado por el doctor Camero Ramos ${ }^{11}$, únicamente resaltaremos los datos globales:

\begin{tabular}{|l|r|r|c|c|}
\hline & Nobleza & Clero & Municipio & $\begin{array}{c}\text { Pueblo (fane- } \\
\text { gas) }\end{array}$ \\
\cline { 2 - 5 } Secano ............. & 6.862 & 3.893 & 2.537 & 2.959 \\
Regadío ............ & 326 & 225 & - & 127 \\
Olico ............... & 3.164 & 1.978 & - & 1.568 \\
Vid ............... & 1.175 & 1.091 & - & 1.094 \\
\hline
\end{tabular}

Analizando este cuadro-resumen vemos cómo destaca el mayor número de tierras en manos de la nobleza (duque y otros miembros de la nobleza, incluyendo los hidalgos, es decir todas las personas a cuyo nombre antecede «don»). En cuanto al municipio, las 2.537 fanegas pertenecen al Caudal de Propios.

Destacando a los mayores hacendados, el primer lugar está ocupado por el duque de Sessa y conde de Cabra, con 3.296 fanegas, lo que supone algo más del $10 \%$ del total.

Concluyendo este apartado podemos destacar la inexistencia de grandes propietarios, a excepción del duque $-\mathrm{y}$ éste no supera la décima parte del territorio-. Destaca el predominio de las propiedades de la nobleza con respecto al resto de estamentos; y entre los nobles, los cuarenta y un mayores propietarios se reparten el $50 \%$ de las tierras.

Ibidem.

10 A. López Ontiveros, Emigración, propiedad y paisaje agrario en la Campiña de Córdoba. Barcelona 1974, p. 502-507.

11 J. Camero Ramos, La evolución de la propiedad rural en Cabra (1752-1852), tesis doctoral leída en la UNED el 12 de noviembre de 1987 (inédita). 
Con referencia a la ganadería, a continuación presentamos el cuadro-resumen:

\begin{tabular}{|c|c|c|c|c|}
\hline \multirow{2}{*}{ Tipo } & \multicolumn{2}{|c|}{ Número de cabezas } & \multicolumn{2}{|c|}{ C. de vientre } \\
\hline & Ecles. & Seglar & Ecles. & Seglar \\
\hline Vacuno & 100 & 1.200 & 20 & 180 \\
\hline Yeguas & 50 & 300 & 6 & 34 \\
\hline Cerdos & 550 & 3.050 & & \\
\hline Jumentos & 250 & 550 & & \\
\hline Cabrío .... & 650 & 1.350 & & \\
\hline Ovejas & 2.000 & 7.000 & & \\
\hline Mular & 12 & 188 & & \\
\hline Colmenas .................... & \multicolumn{4}{|c|}{206 (sin especificar) } \\
\hline
\end{tabular}

En cuanto a los sectores secundario y terciario, podemos señalar que ambos en el Antiguo Régimen giraban en torno al primario: las materias primas, agrícolas o ganaderas eran transformadas por una «industria» predominantemente artesanal; al mismo tiempo lo que hoy conocemos como "sector servicios" - al margen de una mínima burocracia y escasos miembros de profesiones liberales - estaba dedicado al transporte o venta de materias primas o productos elaborados.

Con referencia a la comercialización de las materias primas, debido al elevado número de huertas que posee la villa, permite el autoabastecimiento de productos hortícolas y su "exportación" a otros pueblos. Sin embargo, en determinados momentos, se plantean problemas de abastos. Un ejemplo aparece en la segunda mitad del XVIII cuando el corregidor $^{12}$ plantea la situación. La máxima autoridad municipal quiere demostrar a sus vecinos que el Municipio puede autoabastecerse, pues «... el abasto y mantenimiento de los pueblos, mayormente en aquellos que dan de sí frutos suficientes como sucede en el término de esta villa que produce bastante proporción de frutas y vituallas por exceder dicho su término de trescientas huertas...»; sin embargo, en ocasiones «... se experimenta escasez o bien porque no se siembra la tercera parte del terreno de sus huertas de hortalizas en contravención a reales órdenes de Su Majestad y Auto de Buen Gobierno Público en esta Villa...", y en

12 Archivo Municipal de Cabra (en adelante AMCa.), Leg. 51, exp. 30. Auto de 15 de agosto de 1777. 
estas circunstancias sucede que las frutas y hortalizas se «... extraen a otros pueblos en perjuicio del común...". Para evitar estos inconvenientes el corregidor obliga a todos los hortelanos a plantar la tercera parte del terreno que cultivan de «... hortalizas, legumbres y vituallas de las que corresponden a los respectivos tiempos de cada año conforme a ordenanzas, costumbres y prácticas de este pueblo...», y una vez que la plaza pública esté perfectamente abastecida, sí se permite la comercialización de los frutos a otras localidades.

Los hortelanos tienen la obligación de acudir diariamente en persona o mediante sus mozos o sirvientes a la plaza pública de la villa «... luego que sea de día próximo a salir el sol hasta la hora de misa mayor..." a vender sus productos; una vez allí han de ajustarse «... en todo a las licencias y posturas, peso y medida...", y tras la misa mayor los hortelanos, ya abastecida la villa, pueden vender sus productos a otros pueblos $^{13}$, aunque controlados por la Correduría de Lonja.

Otro aspecto interesante es el relacionado con las industrias transformadoras existentes. El Catastro reseña la presencia de ocho molinos harineros, veintiún molinos de aceite en el término y ocho en el casco urbano, generalmente en manos del duque, de personajes de la nobleza o eclesiásticos; $y$ finalmente hay seis bodegas para almacenar indistintamente aceite y vino.

Además de los molinos y lagares encontramos pocas industrias:

- En el siglo XVIII hay dos batanes, el mayor y más próximo a la villa es propiedad del duque.

— La tenería y el tinte pertenecen igualmente al señor de la villa.

Otra actividad de gran importancia es la referida a la cocción del pan: de los seis hornos existentes, cuatro son del duque.

El hornero es el arrendador del horno, que generalmente no amasa directamente el pan sino que lo hornea. El panadero es el amasador, y tiene la potestad de venderlo directamente o distribuirlo por tiendas. A

13 Ibidem. 
mediados del siglo XVIII los panaderos registrados en Cabra eran 40, siendo nombrados por el Consejo.

Un suceso interesante sobre la panificación se produce en 1771. En este momento, oficiales asalariados en los hornos de la villa, asistidos por el procurador, presentan al Concejo un memorial para que se prohiba el trabajo los domingos y festivos, y que en las vísperas se dupliquen los amasijos «... y que cuando se note alguna falta de insuficiencia de pan en este forzoso caso, con aviso de los mismos panaderos, estaremos prontos a sufragarla, caldeando nuestros hornos a cualquier hora y tiempo de dichos días...". Esto demuestra que el pan se elaboraba diariamente ${ }^{14}$.

La argumentación de los oficiales horneros se basa en un deseo, no de descanso voluntario sino "... en la observancia por el único deseo a que... nos obligó la Fe Católica y a sus preceptos divinos y eclesiásticos...", y así "... les dediquemos como cristianos católicos en obsequio del Divino Culto y no en servicio de nuestras causas...". Como observamos, los trabajadores se acogen a la norma dictada por la Iglesia Católica para tener un día de descanso a la semana; lejos están las futuras conquistas del movimiento obrero en el que no se han de argumentar preceptos religiosos para conseguir un día de descanso semanal. La declaración de un testigo ${ }^{15}$ hace constar que los horneros nunca han trabajado «... los días festivos de precepto... pues siempre, y en todo tiempo los han guardado, así por habérselo mandado los señores vicarios, como por haber sido costumbre que en tales días se abstengan todos del referido trabajo... en todos los pueblos del reino de Córdoba y especialmente en la ciudad de Lucena...».

Esta testificación a favor de los oficiales horneros es rebatida por los panaderos ${ }^{16}$, argumentando los perjuicios que la situación acarrearía, puesto que «... los que tenemos que hacer dos o tres amasijos, se nos impide su ejecución, a causa de que se necesitan personas que ayuden, y a la referida hora no quieren concurrir por no transitar de sus casas a las nuestras, pues las que se ocupan de ello son mujeres doncellas...", y suplican «... se sirva mandar se les haga saber a dicho horneros guardar el estilo referido, admitiéndonos y cociéndonos el pan después del

\footnotetext{
${ }^{4}$ Ibidem, Leg. 51, exp. 27.

5 Declaración de Tomás Mediavilla, arrendador de hornos.

Declaración de Miguel de Rivas.
} 
mediodía (en domingos y festivos), esto pasado el tiempo de Cuaresma y en él para que tengan lugar de oír los sermones, desde las oraciones, pues así conviene al bien público y justicia que pedimos...».

A pesar del «boicot» llevado a cabo por los horneros (no cocer el pan los domingos hasta las diez de la noche, quemar o dejar poco cocido el pan, etc.), el Consejo por sentencia dictada en 1 de junio de 1772 acuerda «... que los domingos y días de fiesta los horneros principien a cocer el pan a la hora de las oraciones...».

Además de las industrias panificadoras había en la villa dos hornos de «cocer teja», ambos en manos de particulares.

Las actividades artesanales también aparecían vinculadas a la economía rural, no ya por la utilización de materias primas procedentes del sector primario sino porque los jornaleros -o trabajadores del campo en general- estaban dedicados a la industria gran parte del año.

Tampoco podemos hablar de una importante estructura gremial, pues apenas existian artesanos en algunas de las actividades industriales ${ }^{17}$. En los diferentes oficios - tejedores, turroneros, curtidores, tintoreros, caldereros, zapateros, etc. - se encuentran uno o dos maestros mientras que desciende el número de oficiales y apenas hay aprendices.

Un caso interesante lo encontramos tanto en albañiles como en bataneros; había un maestro batanero en cada uno de los batanes mientras que «... no hay ni oficiales ni aprendices en este ejercicio porque la gente que ayuda a los maestros en dichos batanes son jornaleros del campo...». Igualmente los nueve maestros de albañil han de utilizar jornaleros como ayudantes y los oficiales del cardado de la lana, por ejemplo, sólo trabajan en su oficio cuatro meses al año y el resto del tiempo lo ocupan como trabajadores del campo.

Esto nos permite reiterar la inexistencia de una fuerte estructura gremial, en principio por la imposibilidad física de reunir obreros en cada uno de los gremios. Si a esto unimos la falta de oficiales y aprendices, podemos ratificar la relación del artesanado con el mundo rural en esta localidad.

17 Respuestas 32 y 33 del Interrogatorio General del Catastro de Ensenada. 


\section{COMERCIALIZACIÓN DE LOS PRODUCTOS MANUFACTURADOS}

El principal producto elaborado para el abasto del común es el pan. Hemos observado ya la inexistencia de panaderos, lo que reafirma el Catastro al destacar que «... no hay panaderos por venderse el pan en plazas, casas de panaderos o donde más comodidad tienen...» ${ }^{18}$.

Sin embargo en períodos de crisis de subsistencias se prohibe a los panaderos la venta directa del pan, como manda el corregidor en auto de 7 de mayo de 1708. En él se dispone que ningún panadero pueda vender pan cocido en sus casas «... si no es en la tienda que él quisiere y señalare ante el presente escribano a donde todos se han de registrar dentro de segundo día, así para que conste de los que tienen y ejercen este oficio como para que hagan la declaración de la tienda donde han de vender dichos panes, así las de especieria como las de verdulerías...» ${ }^{19}$. Esta situación es similar a la planteada ya años antes con el registro de horneros y panaderos. El auto continúa señalando que todo el pan que, después de cocido, fuese llevado a casa de los panaderos «... desde luego su merced lo dé por perdido con la misma aplicación y mande que los horneros que lo cocieran y tableras que lo porteen no lo envíen ni lleven después de cocido a las casas de dichos panaderos, si no es a las referidas tiendas que ellos les hubieren señalado y han de señalar ante el presente escribano...”.

Todas estas medidas se encaminan a evitar la salida del pan amasado de la villa, al igual que el trigo o la harina. Exclusivamente se permite sacar pan a los «trajineros» para el sustento de un día.

El corregidor justifica nuevamente estas decisiones no por la faita de trigo que hay en el reino, pues abunda en muchos lugares, sino que en Cabra es «... la labor de su término tan corta y necesita de entrada de granos en los años de malas cosechas...".

Otro problema reflejado en el auto por la máxima autoridad municipal es la compra que panaderos y otras personas hacen del trigo que los trajineros llevan a la villa. No seria esto ilegal si el lugar de venta fuese

18 Respuesta 29 del Interrogatorio General del Catastro de Ensenada.

19 AMCa., Leg. 51, exp. 8. 
la plaza pública - centro de compraventa-; sin embargo, las transacciones se efectúan en caminos y calles antes que los productos sean registrados. El incumplimiento de la norma lleva aparejada una multa de diez mil maravedíes.

- El vino se vende en nueve casas particulares. Para la venta del resto de bebidas alcohólicas hay dos tiendas de licores y tres mesones, uno dependiente del duque $y$ el resto propiedad de la nobleza igualmente.

- El duque percibe los derechos correspondientes a las pescaderías y carnicerías públicas.

- La feria anual se celebra el primero de noviembre.

- Quedan pocos establecimientos comerciales por reseñar: catorce especierías, dos confiterías «... en las que se venden diversos dulces industriales para el gusto y la delicadeza de las personas que los quieren usar.... ${ }^{20}$, y cuatro tiendas de ropa donde se venden lienzos, paños de las fábricas de Castilla y Valencia, damascos, tafetanes, tapices y, finalmente, paños fabricados en Cabra.

- Los encargados del transporte e intermediarios en el tráfico de mercancías son los arrieros, encontrándose dieciséis registrados en el Catastro ${ }^{21}$. Junto a éstos se hallan veintiún cosarios «... que se ocupan en el acarreo de cal, ladrillo, yeso, maderas y otros portes de diferentes géneros y en diversas ciudades y villas por tener éstos sus carretas para dicho ejercicio..." ${ }^{22}$. Cuando el trabajo escasea, los cosarios utilizan las caballerías para roturar el campo.

Concluyendo podemos señalar que la tierra - la actividad primariaes el fundamento de la economía en esta villa.

\footnotetext{
20 Respuesta 32 del Interrogatorio General del Catastro de Ensenada.

21 Ibidem.

22 Ibidem.
} 


\section{LA PESTE EN CABRA (1648-1651)}

\section{Primera fase: la epidemia cerca la villa}

Planteada la situación de la villa egabrense en la Edad Moderna, vamos a analizar uno de los episodios habituales en esta época, la epidemia de peste que entre 1647 y 1651 afectó a la zona mediterránea y a Andalucía.

La primera noticia que llega a Cabra sobre el contagio pestilente proviene del oficio remitido por don Gregorio de Chaves y Mendoza, corregidor y justicia mayor de la ciudad de Córdoba quien indica los acuerdos tomados en el Cabildo celebrado el 21 de abril de 1648; en aquél se notificaba la existencia de la enfermedad en Valencia y Murcia y se marcaban las pautas para la prevención y guarda del contagio.

Las medidas a tomar serían similares en todas las localidades cordobesas y abarcaban diversos aspectos:

- A nivel espiritual se acuerda «... acudir a Dios nuestro Señor que con su gran misericordia y clemencia conservase a esa ciudad de la salud que gozó y la librase de semejante contagio y se encomendasen los prelados... para que se hiciese memoria... y se repartiesen las limosnas...", suplicando la ayuda al obispo para llevar a cabo tales acciones.

- La profilaxis se recomienda a un doble nivel: por una parte, cercar la villa dejando abiertas únicamente algunas puertas vigiladas con guardias para la entrada y salida de personas y mercancías en un intento de evitar la entrada de los procedentes de las zonas infectadas; por otra parte se manda limpiar la ciudad de toda inmundicia -incluyendo la eliminación de los gusanos de seda criados en el recinto urbano- ${ }^{23}$.

Recibidas estas noticias por el conde de Cabra rápidamente éste envía una carta en 22 de abril de 1648 a don Antonio de Villalba, alcalde mayor egabrense, en la que le notifica el contagio y le urge para la rápida toma de medidas.

23 AMCa., Sanidad, epidemias, Leg. 168, exp. 1. 
El 29 de abril se dicta por el alcalde mayor el primer auto de Buen Gobierno, ordenando tapiar las salidas existentes hacia el exterior del casco urbano ${ }^{24}$. Así en las cuatro puertas importantes de la villa - Santa Ana, Baena, Priego y Córdoba- se van a colocar comisarios; y en la principal, la de Córdoba, «... estará el Justicia, donde se ha de dar licencia para que entren (personas y mercancías), si alguna vez no la tienen y entran serán castigados con cincuenta mil maravedíes y dos años en presidio (para el hombre noble) y al hombre llano de vergüenza pública y seis años de galeras...».

No obstante la operación de cercado de la villa no será tan rápida como se presumía, pues en enero de 1649 el corregidor necesita insistir en un nuevo auto por el que demanda a regidores y jurados de la guarda de las barreras que tapien definitivamente las calles que aún no lo están, así como a los vecinos propietarios de «... postigos y paredes caídas y por bardar que dan al campo las tapen, alcen, barden y reparen de manera que no se pueda entrar por ellos..." bajo pena por incumplimiento de 10.000 maravedíes y vergüenza pública.

La potestad jurisdiccional del duque queda claramente demostrada al nombrar hombres de confianza para el control de las puertas así como al crear un órgano colegiado para la guarda del contagio, la Junta de Salud, en 9 de junio de 1649. Esta Junta se ha de reunir obligatoriamente todos los días en el castillo ducal, imponiendo una multa de dos ducados al que no acuda.

Tras un año de medidas preventivas la epidemia no ha afectado a la población egabrense, aunque aquella parece cercar la villa. Así en enero de 1649 el duque de Arcos informa de la existencia de peste en Cádiz, y en marzo ha llegado a Málaga por el sur y a Cazorla y Quesada en Jaén por el este, en abril Utrera está contagiada; dos meses más tarde están afectadas Palma del Río, La Puente de Don Gonzalo (actual Puente Genil), Espejo y Priego, localidades cordobesas próximas a Cabra $^{25}$.

Estas circunstancias obligan a reforzar las medidas higiénico-sanitarias de la población:

24 Ibidem: «se cercasen y bancasen las calles para que no entrase en ellas ninguna persona de ninguna parte si no fuese trayendo un testimonio de sanidad de la parte y lugar donde ha asistido".

25 AMCa., Sanidad, epidemias, Leg. 168-2, exp. 4. 
- Las personas que viven en el campo son recluidas en el recinto urbano, excepto los molineros. Para vigilar el cumplimiento de estas normas se colocan guardias en el campo.

- Los campesinos que hayan de salir al campo deberán recoger un sello con las armas de la villa en las puertas de la ciudad. Este sistema no funcionará por «... no ejecutar los comisarios de las puertas las órdenes que tenían...” ${ }^{26}$, así que se modifica el sistema con la presencia en cada puerta de un libro abecedario donde se anota si las salidas se hacen por un día 0 dos ${ }^{27}$. La finalidad de estas acciones reside en la necesidad de impedir que los trabajadores pudiesen llegar a zonas de contagio; esto implica igualmente el registro de pastores cada tres dias ${ }^{28}$.

- La rigidez y dureza extrema de las medidas se debía al intento de evitar el contagio, llegando la situación a tal gravedad que es considerada por el duque «... autos de guerra así en las ejecuciones como en las promulgaciones...» ${ }^{29}$. A pesar de todo el señor tenía absoluta certeza del incumplimiento de las órdenes, pues algunos súbditos acudían a lugares infectados para comerciar «... contra las órdenes, contra la razón y la justicia siendo traidores a su misma patria y que siendo por vil codicia solicitar no sólo la muerte suya sino la de todos, sin que hayan bastado los castigos que se han hecho de azotes en algunos, habiendo por mi obligación y mi conciencia y por el amor que debo a mis súbditos de solicitar el reparo de maldad tan grande y poner remedio más eficaz, no habiendo bastado los puestos y siendo menor inconveniente que la muerte universal de tantos la particular de delincuentes tan atroces, mando que públicamente se pregone para que se venga noticia de todos que pena de cien azotes y diez años de galeras, ninguno de los vecinos de ese lugar sea osado de pasar al término ajeno sino fuera con testimonio o licencia expresa mía y del Conde, mi hijo, y de la Junta, y si fuera hombre en quien no quepa esta pena (se le impondrán) cincuenta ducados para gastos de la Junta de Sanidad y presidio por seis meses.... ${ }^{30}$.

Junto a estas medidas que podemos considerar de carácter general se dan unas normas de carácter interno, bien referidas a la higiene, a la alimentación o para circunstancias especiales.

\footnotetext{
Decreto del duque el 10 de mayo de 1649 .

Ibidem.

Decreto del duque el 21 de enero de 1649.

Decreto del duque el 6 de junio de 1650.

Ibidem.
} 
- En cuanto a la higiene se toman los siguientes acuerdos:

- Limpiar las calles y pertenencias de cada uno, evitando al mismo tiempo arrojar «... neciedades ni agua por los caños, que causan olor por el daño que de lo susodicho puede causar y asímismo no se entre ganado de cerda ni otro que cause daño..." ${ }^{31}$.

- Que no se críen gusanos de seda en el casco urbano.

- A los pasajeros que acuden a la villa se les prohibe la entrada de ropa, so pena de 50 ducados.

- Igualmente se ponen trabas a las mudanzas de casa llevadas a cabo por los vecinos ${ }^{33}$.

- También un auto de 4 de julio de 1649 acuerda «... no dejar salir a ningún muchacho de doce años abajo ni a ningún mayor en los días de entre semana si no fuera mujer principal conocida de dichos comisarios... y en los días de fiesta dejen salir a todos para que tengan algún desahogo; y para que tengan donde puedan lavar sin salir de esta villa los días entre semana se le notifique al Alcalde del Agua eche todo el Caz (acequia) por el de esta villa todas las noches (so) pena de dos ducados para gastos de su morada... (y) que todos los vecinos de esta villa que junto a las puertas de las casas de su morada tuviesen algún animal muerto que cause mal olor lo quiten y entierren (bajo) pena de un ducado para gastos de la peste... (y) que ningún criado ni otra persona eche inmundicias ni vacíen los servicios en las calles (so) pena de cien azotes... y su amo que lo mandare pena de dos ducados para gastos de la peste...".

- Los alimentos también se ven sometidos a las prohibiciones en beneficio de la salud de los habitantes. Las medidas son las siguientes:

- Que ninguna persona pueda vender queso fresco, leche,

31 Auto del 5 de mayo de 1648 .

32 Auto del 13 de julio de 1648 .

33 Decreto del duque de 30 de junio de 1649 . 
habas, cardillos, alcauciles, recosidos «... ni otros mantenimientos que fueren contrarios a la salud.... ${ }^{34}$.

- Igualmente se prohibe a los vecinos comprar mercancías fuera de la puerta de Córdoba, pues está prohibida su entrada «... so pena de vergüenza pública siendo persona en quien se pueda ejecutar, y no lo siendo cincuenta ducados... ${ }^{35}$.

- Igualmente se plantean medidas coercitivas en momentos de grandes aglomeraciones, como sucede en las fiestas y ferias. Veamos dos casos:

- En un auto dictado el 22 de junio de 1648 el corregidor «... dijo que por cuanto esta dicha villa y sus vecino se están guardando del contagio de peste que dicen padece la ciudad de Murcia y demás contenidas en la memoria de los autos, y mañana, víspera del Señor San Juan de junio suele salir mucha gente al campo y por que no se puede tener la cuenta que es necesario con las personas que salen y entran y particularmente de noche de que se puede ocasionar grande daño a esta dicha villa y sus vecinos y para que de cualquiera estado, calidad $y$ condición que sea salga al campo mañana veinte y tres del presente y si alguno saliere, entre en esta dicha villa antes de la ocasión que es a la hora que se han de cerrar las puertas de las barreras so pena que los que no vinieren se quedarán fuera en el campo, y demás de lo susodicho incurren en pena, el hombre noble de cincuenta mil maravedíes para la Cámara de su Excelencia... y el hombre llano de vergüenza pública... ${ }^{36}$.

- Otro ejemplo lo encontramos en el Decreto que el duque envía al corregidor en fecha 13 de junio de 1648 impidiendo la celebración de la «... Feria y así mandaréis en la Junta no dejen entrar a ningún mercader, platero ni buhonero aunque traigan testimonio (so) pena de cincuenta ducados...».

Lógicamente en períodos de epidemias los arrieros, mercaderes y comerciantes en general son personas a vigilar; no obstante en este

34 Auto del 4 de julio de 1649.

35 Auto del 24 de mayo de 1650.

36 Auto del 22 de junio de 1648 . 
momento encontramos un colectivo susceptible de introducir el contagio en la villa según las autoridades: son los religiosos, pues «... de religiosos hay más reactarse (sic) que de otros ningunos, respecto de que por sus profesiones y ayudas en estas ocasiones a los contagiados ha sido el motivo en las pestes pasadas de pegarse y porque me parece justo que en tiempo tan peligroso no salgan de sus conventos ni vaguen por las provincias, y creo lo harán; así os advierto el singular cuidado que es menester en no recibir ninguno..." ${ }^{37}$. El duque no actúa sin conocimiento de causa, pues «... ropa que unos frailes metieron de Valencia en el Puerto de Santa María se tiene por cierto ha ocasionado la peste que hoy se produce en Andalucía...» ${ }^{38}$.

Estas suspicacias contra los clérigos se completan con un decreto del duque en 8 de febrero de 1650: "Para mayor seguridad de que ninguna persona pueda entrar ropa ni otra cosa de las prohibidas, daréis orden en las puertas para que no dejen salir a ningún clérigo así sacerdote como capellán que gozan del fuero eclesiástico, y si salieren no se les dejará volver a entrar (bajo) pena de cincuenta ducados al comisario que faltase a esta orden... ${ }^{39}$.

En otras ocasiones el estamento eclesiástico colabora en las denuncias, aunque por obligación. Un documento interesantísimo es la carta que el duque envía al corregidor el 7 de junio de 1649:

«Habiendo persona celosa del bien de estas repúblicas, que ignoro quién sea porque acudió a un confesor para que de bajo del secreto de la dicha confesión no pudiese decir quién era, pero que daba beneplácito para que me diese cuenta de la mayor maldad que puede pensarse de cristianos contra su misma patria que siempre debe mirarse como nadie, $y$ es que se concertaron dieciocho para ir a Sevilla, como con efecto dicen lo han hecho, según el tiempo que salieron parece volverán dentro de dos o tres días poco más o menos, que irían a aprovecharse de la ropa que pudiesen de todos los que hubiesen muerto de peste y mercancías que hallasen, y que los otros ocho que habían quedado en el lugar lo ayudarian a meterla; y procurando cumplir con el oficio en que Dios me puso de padre de mis súbditos, deseando averiguar y castigar maldad tan atroz y librar tantos inocentes, ordené se empadronasen todos los hombres de diez años arriba, para que por aquí se averiguase los que faltasen, y no habiéndose podido averiguar como

37 Decreto del duque de 18 de enero de 1649.

38 Decreto del 11 de mayo de 1649.

39 Decreto del duque de 8 de febrero de 1650. 
convenía, he parecido (sic) hacerlo público en el lugar para que cada uno conforme a sus obligaciones o bien en el amparo de sus mujeres, hijos y patria, dando cuenta de tan grande maldad que a cualquiera que lo descubriese se le darán cien ducados y se le perdonará, aunque sea de los mismos cómplices, dentro de dos días, advirtiendo que si se le averiguase que lo ha sabido y no ha dado la dicha cuenta, pena de doscientos azotes y de galeras perpetuas y perdimiento (sic) de bienes, y si fuere noble pena de perdimiento de bienes y al peñón de por vida; todo lo cual mando se pregone públicamente en las plazas y partes públicas de estas villas; y que si fuera cómplice y no lo declarase incurre en pena de la vida y perdimiento de bienes...".

\section{Segunda fase: la epidemia llega a Cabra}

La peste no llega a Cabra, hasta el punto de que desde el 21 de octubre de 1650 hasta el 5 de junio de 1651 la situación es de total tranquilidad. No obstante se inicia una segunda fase mucho más trágica cuando el 6 de junio de 1651 el duque dicta un nuevo decreto al corregidor, comunicándoles un nuevo brote pestilente en Priego, localidad situada a $20 \mathrm{Kms}$ de Cabra, y muy vinculada con la egabrense por ser ambas pertenecientes a la rama señorial de los Fernández de Córdoba.

A pesar de la rapidez y urgencia de las medidas tomadas, el día 8 de junio la terrible parca llega a la población:

«En la villa de Cabra en ocho días del mes de junio de mil seiscientos y cincuenta y un años su Merced Don Antonio Carvajal, Corregidor de esta villa, digo que atento que en esta dicha villa hay enfermedad de tabardillo malicioso y agudos de que mueren algunas personas..." ${ }^{40}$.

Esta situación lógicamente cambia todos los planteamientos anteriores, ahora las medidas no son para evitar la enfermedad, sino para tratar de que afecte aquella lo menos posible.

Las primeras medidas tomadas consisten en separar a los enfermos de los sanos; para buscar una ubicación a aquéllas se realizará un Cabildo. Se mantiene también aislada la ciudad.

40 Auto del 8 de junio de 1651. 
El auto de 9 de junio confirma la aparición de la peste: «... de presente hay en esta villa por la misericordia de Dios y nuestra que de [con]tagio en algunas landres conforme ha reconocido y ha constado por declaración [de] médicos, y en algunas casas que ha tocado el dicho contagio sea quemada toda la ropa que se ha hallado en ellas...».

\section{CREACIÓN DEL HOSPITAL DE CONTAGIO}

Una vez que la enfermedad penetra en la villa, y para que las medidas de prevención, cura y aislamiento sean más efectivas el Cabildo el 19 de junio de $1651^{41}$ toma el acuerdo de crear un Hospital en la ermita de San Juan Bautista.

A pesar de la existencia en la villa de un importante hospital, el de la Caridad y San Rodrigo, administrado por la Orden Hospitalaria de San Juan de Dios, se recurre a una ermita, la de San Juan del Cerro, ya utilizada en anteriores procesos epidémicos.

El motivo de esía elección se basó en que dicha ermita estaba situada en las afueras del casco urbano, mientras que el Hospital de la Caridad y San Rodrigo, ubicado en el centro de la ciudad, continuaría con la atención de otros enfermos. Es importante destacar este hecho, pues en Córdoba se usaba el Hospital de San Lázaro - de la Orden de San Juan de Dios- como hospital de contagio debido a su situación extramuros.

De este modo los miembros de la Orden Hospitalaria en Cabra podrían quedar desvinculados del tratamiento, aunque algunos hermanos aparecerán entre los fallecidos - tal vez al actuar como enfermeros-. Además aportarán a la ermita de San Juan Bautista cuatro camas completas, lo que será posteriormente motivo de pleito con el Concejo de la villa cuando, pasada la epidemia, el prior fray Sebastián Malo de Molina reclame al Concejo los 120 ducados en los que estaban tasadas dichas camas $^{42}$.

41 Actas Capitulares de 19 de junio de 1651

42 AMCa., San Rodrigo, Leg. 13, exp. 1. 
La creación del Hospital de San Juan Bautista se llevará a cabo el día 19 de junio de 1651, una vez fallecidas ya algunas personas. Además de utilizar la ermita, las calles que la rodean son cercadas y sus casas utilizadas como lugar de convalecencia.

Otras ermitas, como la de San Sebastián o la del Calvario, más alejadas del casco urbano, servirán de lugar de cuarentena.

Igualmente se toman otra serie de medidas para dar fin al contagio:

- Se cierran las casas de los enfermos contagiados, evitando igualmente que ningún vecino, entrando por los corrales, pueda coger la ropa de los enfermos «... so pena de la vida...» ${ }^{43}$.

- Que ningún vecino se mude de una casa a otra «... so pena de doscientos azotes o doscientos ducados para gastos del hospital...» ${ }^{44}$.

- Los perros y gatos han de ser exterminados «... porque algunas personas (se han tocado del contagio) y se han llevado al Hospital a curarse y se han cer[cado] (sus casas) y en ellas hay algunos gatos y perros que echan la falta de los dueños [y] pueden pasar a otras casas sanas, lo cual puede ser causa de extenderse el dicho contagio... que todos los vecinos de esta villa maten todos los perros y gatos así de las casas cerradas como de otras cualesquiera casas... so pena de seiscientos maravedíes para gastos del hospital...».

- La ropa de personas no contagiadas se ha de colocar en habitaciones aisladas dentro de las casas, tapiando posteriormente sus puertas. Así esta ropa podía ser utilizada con posterioridad.

- El duque de Sessa se encargará de financiar la llegada de un médico y un cirujano malagueños, muy habituados a la enfermedad.

Hasta el momento hemos analizado las decisiones tomadas por la jerarquía municipal, pero ¿cuál es la reacción de los habitantes ante el contagio? Además de las plegarias y rogativas tradicionales, la gente pretende huir de la villa, y lo más cercano es el campo. Esto obliga al

43 Auto del 19 de junio de 1651 .

44 Ibidem. 
corregidor a dictar un auto el 26 de junio de 1651, pues huyen tarto los vecinos como las personas encargadas de vigilar las puertas, bajo pena de 200 ducados.

\section{FUNCIONAMIENTO DEL HOSPITAL. ASISTENCIA, PROFILAXIS}

El proceso asistencial seguido contra la enfermedad es el siguiente:

- Una vez dictado el diagnóstico por el médico, el enfermo es llevado al Hospital de contagio; su vivienda era cerrada, se "purificaba» la llave con vinagre y le era entregada al corregidor; su ropa era llevada a las afueras de la villa y quemada.

- El médico no entraba al Hospital de contagio, sino que dos veces al día acudía a las inmediaciones de aquél e indicaba al cirujano los «... cordiales, pócimas y defensivos... ${ }^{45}$ que había de aplicar. Junto al cirujano en el Hospital trabajaban un sangrador, varios sirvientes como enfermeros y un confesor capuchino.

- Para purificar los cuerpos y evitar el contagio se daban lavados con vinagre y vino y «... sahumerios con pólvora, romero, enebro, ciprés y otros...»; las casas eran desinfectadas con cal viva.

\section{ENFERMOS: DIFERENCIACIÓN SOCIAL}

En el desarrollo del tema hemos observado cómo se aprecian claramente las desigualdades entre los diferentes estamentos al distinguirlos en las penas impuestas: a nobles o hidalgos, por ejemplo, no se les aplican castigos corporales o galeras. Estas mismas desigualdades apa-

45 Declaración de Francisco de los Aires, cirujano, en 29 de agosto de 1651. 
recen al tratar un apestado según pertenezca al pueblo llano o al estamento privilegiado.

En un auto promulgado el 3 de agosto de 1651 se prohibe a los vecinos la ocultación de la enfermedad, hecho habitual, pues «... algunos vecinos de esta dicha villa han enterrado en sus casas muchas personas de sus familias que han muerto de contagio sin dar cuenta a su merced... ${ }^{46}$, por lo tanto se exige que todo vecino enfermo sea observado por el médico. Si está apestado ingresará inmediatamente en el Hospital. Al mismo tiempo se prohibe a los boticarios la venta de medicinas para curar el contagio - si no cuentan con la receta del doctor-. Sin embargo en la reunión celebrada el 5 de julio de 1651 por la Junta de Salud se acuerda consultar «... a su Excelencia el Duque mi señor que si lo que Dios no permita toca el achaque en algunos señores sacerdotes o de orden sacro y de las personas de calidad, así hombre que mujeres, que éstas se hallan de curar en sus casas en aposento aparte separado de la gente de la dicha familia sin que se comunique con los demás criados ni gente de la casa, sino tan solamente con la persona que hubiere de asistir con los tales enfermos...".

\section{DESCRIPCIÓN DE DOS APESTADOS}

El doctor malagueño Fernando de Fonseca realizará la única descripción de apestados que conservamos al certificar el fallecimiento de un individuo en el Batán del Duque ${ }^{47}$ :

Había un hombre muerto «... cubierto con un paño recién sacado del telar, desnudo, y llegándolo a ver le halló por todas las señales lívido el cuerpo con máculas pintas, frío como el hielo y todo él [en] horrible disposición con que todos los que mueren del contagio pestilente tienen, y así le vio muerto naturaimente, y tiene por cierto y evidente por la experiencia que tiene de haber visto muchos muertos de contagio, haber muerto de una calentura pestilente y haberse contagiado de su mujer propia, por haberla visto a dicha mujer hoy dicho día en el Hospital con

\footnotetext{
46 Auto del 3 de agosto de 1651.

47 Junta del 30 de julio de 1651.
} 
un tumor tan grande como un huevo en una ingle, en la sustancia del muslo, y con una calentura pestilente, y preguntándoles que cuánto tiempo había que estaba mala, respondió que había nueve días, y de esto infiere que la dicha mujer contagió al dicho marido...».

\section{FIN DE LA EPIDEMIA. CIERRE DEL HOSPITAL. ULTIMAS MEDIDAS} TOMADAS

El 28 de agosto de 1651 se acuerda el cierre del Hospital que «... por la [con]cordia de Dios Nuestro Señor y por la pr[ovidencia] de la Virgen Santísima Santa Mar[ía de la] Sierra su Madre, concebida sin mancha de pecado original, ha más de ocho días que no ha entrado enfermo en el Hospital...», siendo esto asimismo ratificado por los médicos.

Las últimas medidas tomadas son:

- Quemar la ropa de las personas que han estado en contacto con los apestados.

- Purificar las casas de los enfermos, picando las paredes, techos y suelos, enlucirlos con cal viva y ahumarlos; lo mismo se hace en el Hospital.

- Que «... los dos carneros que se abrieron en el dicho Hospital para enterrar los difuntos de dicho achaque, aunque estén muy hondos y mucha tierra encima y fuera de los muros y cercados con tapias para más seguridad, sobre la tierra se hace mezcla de cal y arena y se pisará, con que se asegura que no sal[gan] los vapores de los dichos carneros...» ${ }^{48}$.

\footnotetext{
48 Junta de 30 de agosto de 1651.
} 


\section{CONCLUSIONES}

El paso de la epidemia de peste por la villa egabrense va a dejar muertos -en el Hospital fueron ciento veinte y siete- y su actividad económica bloqueada.

Así la economía de las arcas concejiles va a ser crítica, y como señala don Juan de Paz Lorite, regidor y procurador general del gobierno de la villa en el pleito suscitado por el Convento Hospital de San Juan de Dios sobre las camas prestadas al Hospital de contagio, el Concejo no tiene «... ningunos bienes de que se puedan dar los maravedies que pide la parte del dicho Hospital por estar debiendo a su Merced muy grandes sumas de maravedies sobre que tienen embargados todos sus propios y otros débitos de particulares que es imposible poderlos pagar...” ${ }^{49}$.

Esta situación existe a pesar de multas y requisas durante la epidemia, así como de la utilización del Pósito, de los recargos sobre algunos alimentos - carne y pescado - y de los donativos del duque. La villa de Cabra tardará mucho tiempo en recuperarse, considerando además que en los siguientes años se van a producir crisis de subsistencias y nuevas epidemias en la etapa más grave de la crisis del XVII.

49 Declaración de Juan de Paz Lorite en 4 de agosto de 1655. 


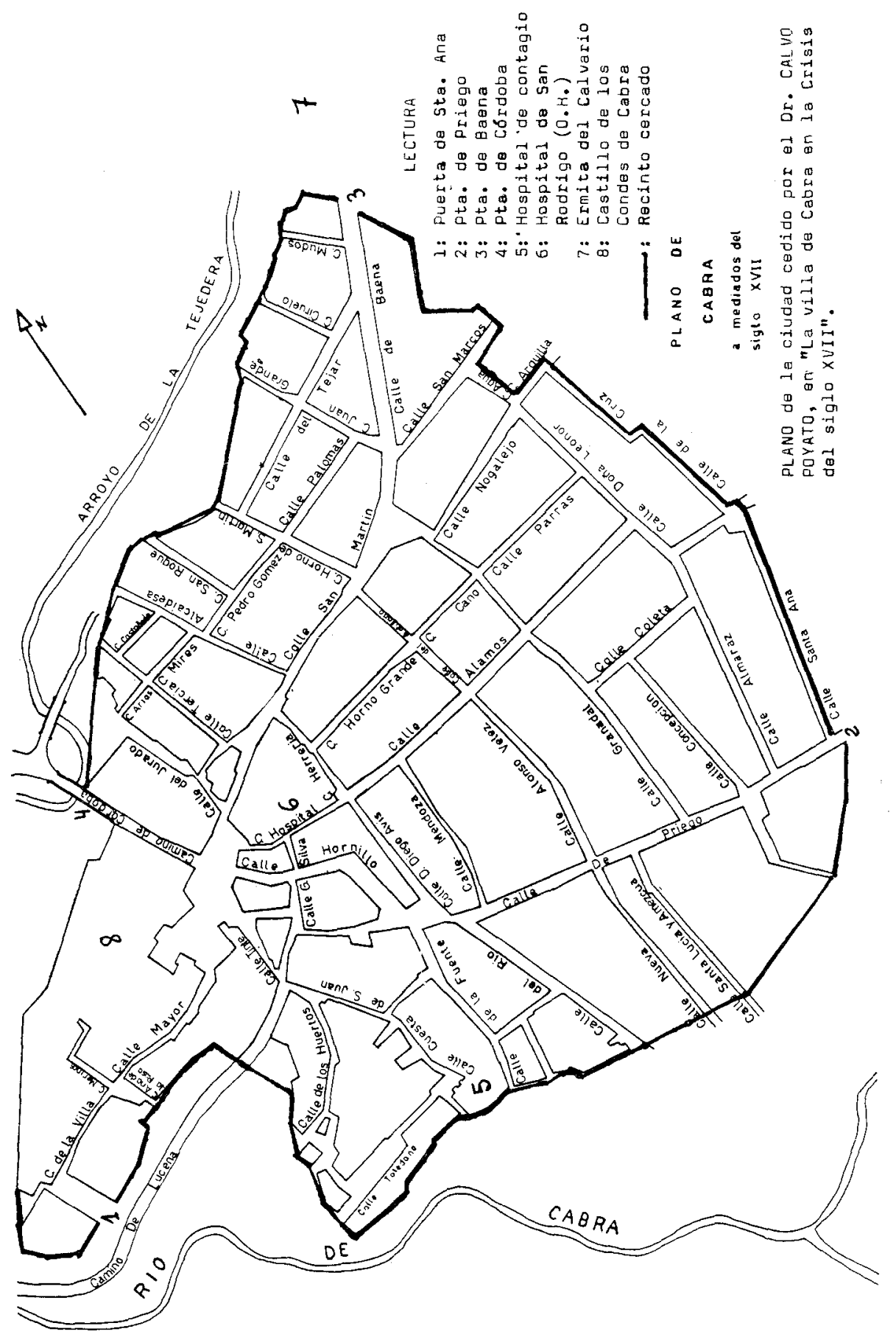

